\title{
EDITORIAL
}

\section{Emotion and Multi-Dimensional Engineering}

\author{
Shuichi Fukuda ${ }^{a^{*}}$ and Monica Bordegoni ${ }^{b}$ \\ ${ }^{a}$ Keio University, System Design and Management, Yokohama, Japan \\ ${ }^{b}$ Politecnico di Milano, Department of Mechanical Engineering, Milan, Italy
}

Yesterday, we believed the future is ours to see, but it becomes increasingly difficult with frequent and extensive changes to predict the future. But on the other side, as Internet of Things indicates, people and even things are getting more and more connected, and enormous amount of information is flying around the world. Therefore, now is the time for a change. We have to create the future.

Engineering is a creative activity to make our dreams come true. We have to get back to the starting point of engineering. In order to make the future ours to create, we have to add contextual meaning to the information. It is a very important role of emotion.

As brain science indicates, the prefrontal region of our brain is deeply related to perception, cognition and emotion. It made clear its executive function is closely related to emotion, which processes crosstemporal and cross-modal information, and it relates our past to the future.

Thus, emotion must be explored from multi-dimensional aspects. If we do not understand the situation in our daily life, we exert a full range of senses. In the same way, we have to integrate all information by utilizing emotion to make a proper step forward.

Eight papers in this special issue are from various fields and provide very different perspectives. Therefore, it is strongly hoped that the reader will find a clue to how they can connect them, and bridge the gap between different fields in order to explore the new world and to create the future.

The first paper, titled "The next stage of engineering: from How and What to Why" by Shuichi Fukuda is a position paper, or it would be better to call it an engineering essay. Engineering is a creative activity to make our dreams come true. That is why we are called Homo Faber (Human makes a tool). We designed and made a tool to realize our dreams. But once we succeeded in making a tool, we forgot our dreams and we devoted ourselves entirely to search for what we can develop with it. Thus, engineering up to now has focused on How and then What. But now we are getting back to the starting point. Why do we want such a product or service? What differentiates humans from animals is that humans can think about the future. So the next stage of engineering is getting away from the animal world and exploring the new world of humans.

The second paper, titled "Unfolding the notion of experience (virtual) prototyping: a framework for prototyping in an experience-driven design process" by Serena Camere and Monica Bordegoni proposes Experience Prototyping. Prototyping has developed from verification to validation. Innovation in (virtual) technology has enabled prototyping the future users' experience, in order to respond to the increasing importance of experience value. Thus, prototyping has opened a door to the new world of experience development.

\footnotetext{
*Corresponding author. Email: shufukuda@gmail.com.
} 
The third paper, titled "Utilizing the Repertory Grid Technique in visual prosthetic design: promoting a user-centred approach" by Stefania Sansoni, Andrew Wodehouse, Angus McFadyen and Arjan Buis proposes a new user-centred data collection methodology based on the Repertory Grid Technique for the aesthetic design of below-knee prostheses. Its uniqueness is while most of the prosthetic design only considers functional aspects, their proposed methodology considers latent emotional needs of prosthetic users. Interview results are translated into measurable aesthetic elements to develop prosthetics that will truly satisfy the users.

The fourth paper, titled "A Mixed Reality system for Kansei-based co-design of highly customized products" by Pierre-Antoine Arright, Santosh Maurya, Kengo Arai, Koyo Moriya and Celine Mougenot describes a newly developed Mixed Reality system for the design of a walking assistive device for the mobility impaired. As needs vary extensively from person to person, the authors introduced modular Tangible User Interface and additive manufacturing with the help of a 3D game engine to develop a truly customized device. They also paid attention to Kansei or emotional aspects by collecting questionnaires and psychophysical measurements, and integrate these results into their Mixed Reality system.

The fifth paper, titled "Cognitive and neural mechanisms of aesthetic sensitivity with regard to product form" by Kazutaka Ueda, Tomohiro Takahashi, Takamasa Noda, Hideyoshi Yanagisawa and Tamotsu Murakami carried out experiments to monitor neural activation using EEG and compared subjective evaluation of a product form (the front of a car) with physiological experiments. They concluded that their approach may lead to the clarification of cognitive and neural mechanism to evaluate the aesthetics of a product.

The sixth paper, titled "A proposal of Kansei database framework and Kansei modeling methodology for the delight design platform" by Hideyoshi Yanagisawa, Sohya Nakano and Tamotsu Murakami is an intermediate deliverable of 2014-2018 SIP (Cross-ministerial Strategic Innovation Promotion Program) of the Japanese Government with NEDO (New Energy and Industry Technology Development Organization) in charge. Prof. Hiromasa Suzuki, University of Tokyo is leading the project. This project is based on the idea of Prof. Noriaki Kano, who classified quality into must-be, one-dimensional and attractive in 1984. The project pursues attractive quality and they call it delight design, and the authors' final goal is to establish delight design platform.

The seventh paper, titled " 'Design for $\mathrm{X}$ ' based on foreseeing emotional impact of meetings with evolving products" by Lawrence Farrugia and Jonathan Borg pointed out that most researches on emotion in design only pay attention to the user, but we should remember that there are many stakeholders relating to product development. Unless we pay attention to their emotions and emotions throughout product lifecycle, we cannot develop products that really satisfy our customers emotionally. The authors carried out experiments using Geneva Emotion Wheel and made it clear that emotions affect operator performance and thus final products. Based on these results, the authors developed the HELM (Human Emotions in Life-Phase Meetings) approach, which takes into account not only functional aspects, but also emotional ones at the same time.

The eighth paper, titled "Defining brand identity through a Kansei-experience approach the creation of the experience framework boards (EFB)" by Daniel Esquivel Elizondo, Carole Bouchard and Carole Favart describes their newly developed Experience Framework Board. They found out that there are very few, if any, research in experience design and Kansei research that deal with brand. The authors regard brand equivalent to personality so that based on the idea of Five Factor Model of Personality, they developed the Framework. Its uniqueness is it gives a holistic view of experience. It will be very useful for designers, engineers and marketers to integrate brand essence at early design stage. The brand personality includes users' value and their behavior. The authors even consider gestures, because interaction is important in evaluating Kansei. The authors demonstrated the usefulness of their Framework by experiments using Kansei cards of images and keywords. 


\section{Author Biographies}

Dr. Shuichi Fukuda is Advisor and Professor, System Design and Management, Keio University, Japan. He received Doctor of Engineering in Mechanical Engineering from University of Tokyo and worked at University of Tokyo, Osaka University, West Virginia University, Stanford University, Cranfield University and the Open University of Japan. He served President of ISPE, Vice President of Reliability Society, IEEE, Deputy Technical Group Leader, Systems and Design Group, ASME and Chair of Computers and Information in Engineering Division, ASME. He is honorary member of JSME, Fellow of ASME, IEICE, ISPE and glory member of REAJ, and member of Engineering Academy of Japan. His main research interest is Emotional Engineering and he published Emotional Engineering, Vol.1-Vol.4 as editor from Springer.

Dr. Monica Bordegoni is full professor at the Department of Mechanical Engineering, School of Design at Politecnico di Milano. She is the coordinator of the Methods and Techniques of Industrial Engineering group and of the Virtual Prototyping Lab. Her main research interests are in the areas of virtual prototyping of products, Virtual Reality technology and systems and their application in the engineering and industrial design sectors, multisensory interaction, product experience, haptic technologies and interaction, emotional engineering. She is currently deputy chair of the Executive Committee of the ASME-CIE Division, and member of the Advisory Board of the Design Society (20152017). She co-chairs the Design Society Special Interest Group on Emotional Engineering. 